\title{
Tendências de pesquisa em políticas públicas: uma avaliação do Programa Nacional de Alimentação Escolar - PNAE
}

\author{
Research trends in public policy: an assessment \\ of the National School Food Program (PNAE)
}

Angelita Pinto Libermann ${ }^{1}$

Geysler Rogis Flor Bertolini ${ }^{1}$

${ }^{1}$ Universidade Estadual do Oeste do Paraná. R.

Universitária 1619, Jardim

Universitário. 85819-110

Cascavel PR Brasil. angel_

libermann@hotmail.com

\begin{abstract}
The scope of the article is to evaluate the research trends of the Brazilian School Food Program (PNAE), by analyzing the papers published in journals on the Brazilian Federal Agency for Support and Evaluation of Graduate Education (CAPES) website in the period from 2008 to 2013. It involved bibliographical research by means of qualitative analysis to detect the most relevant issues addressed and discussed by the program. Ten scientific articles related to the area were selected after reading the abstracts and research topics of the articles and by a search for the following key words: public policy, family farming, school food. Studies related to the PNAE and its impacts were also considered, due to the connection with the activities carried out in Brazilian public policy. The paper presents the issues analyzed and discussed most on the subject during the period under consideration. The conclusion reached is that the main research trends are characterized by the study of strategies for food and nutrition safety, analyzing the composition and acceptance of foods offered to students by an analysis of production, better living conditions and local development of rural producers.
\end{abstract}

Key words National School Food Program, Public policy, Family farming, School food and nutrition, Food safety
Resumo O objetivo do artigo é avaliar as tendências de pesquisa do Programa Nacional de Alimentação Escolar (PNAE), analisando os periódicos disponibilizados pela Coordenação de Aperfeiçoamento de Pessoal de Nivel Superior - CAPES, no período de 2008 a 2013. Pesquisa bibliográfica com a observação dos assuntos abordados mais relevantes, discutidos pelo programa neste período por uma análise qualitativa. Foram selecionados 10 artigos científicos vinculados à área, sendo que a escolha ocorreu pela leitura dos resumos e das questões de pesquisa dos artigos, bem como pela busca das seguintes palavras-chave: políticas públicas, agricultura familiar, alimentação escolar. Estudos relacionados ao PNAE e os seus impactos também foram considerados, devido à ligação com as atividades desempenhadas pelas Políticas Públicas. O artigo apresenta as temáticas mais analisadas e exploradas sobre o tema durante o período considerado. Conclui-se que as principais tendências de pesquisa, se caracterizam pelo estudo de estratégias de Segurança Alimentar e Nutricional, analisando a composição e a aceitação dos alimentos oferecidos aos estudantes, pela analise da produção, melhores condições de vida e desenvolvimento local dos produtores rurais.

Palavras chave Programa nacional de alimentação escolar, Políticas públicas, Agricultura familiar, Alimentação e nutrição escolar, Segurança alimentar. 


\section{Introdução}

O Programa Nacional de Alimentação Escolar PNAE se apresenta como uma estratégia de promoção da alimentação saudável. A alimentação escolar começou a adquirir um caráter mais efetivamente relacionado ao contexto do processo ensino-aprendizagem e assumir a dimensão de prática pedagógica, de ação educativa, visando à promoção da saúde e da segurança alimentar e nutricional. O Programa passou a efetivamente se denominar Programa Nacional de Alimentação Escolar em 1979, e propôs programas de suplementação alimentar dirigidos aos trabalhadores, ao grupo materno-infantil e aos escolares, privilegiando as regiões mais pobres ${ }^{1}$.

O PNAE é o maior Programa de suplementação alimentar da América Latina, tendo em vista o tempo de atuação, a continuidade, o compromisso constitucional desde 1988, o caráter universal, o número de alunos atendidos e o volume de investimentos já realizados ${ }^{2}$.

Constitui-se, basicamente, na oferta de refeições para o estudante do ensino básico, fornecendo um mínimo de $20 \%$ das suas necessidades nutricionais e contribuindo para o crescimento e o desenvolvimento biopsicossocial, a aprendizagem e o rendimento escolar ${ }^{3}$.

Atualmente constitui uma importante estratégia de Segurança Alimentar e Nutricional (SAN), ao promover o Direito Humano à Alimentação Adequada (DHAA) através da alimentação escolar, assim como de várias ações que contribuem para que se possa atingir as metas dos Objetivos de Desenvolvimento do Milênio $(\mathrm{ODM})^{4}$.

Desde os anos 2000, o governo federal estabeleceu que as compras devem ser feitas em uma proporção superior a $70 \%$ dos recursos com alimentos básicos e que as quantidades de açúcar, sal, gorduras totais, saturadas ou gorduras trans deveriam obedecer os limites previstos em legislação².

Suas Diretrizes sugerem o emprego da alimentação saudável e adequada; a inclusão da educação alimentar e nutricional no processo de ensino e aprendizagem; a descentralização das ações e a articulação, em regime de colaboração, entre as esferas de governo; e o apoio ao desenvolvimento sustentável ${ }^{5}$.

Foram eleitos alguns princípios norteadores da execução do programa junto aos estados e municípios: equidade, participação social, universalidade, sustentabilidade/continuidade, compartilhamento de responsabilidades, direito humano à alimentação adequada e respeito aos hábitos e tradições regionais ${ }^{1}$.

Em seus princípios estruturantes o programa tem avançado em direção a consolidar o direito e o acesso à alimentação adequada e saudável no espaço escolar, promovendo e incentivando ações ${ }^{6}$.

Trata-se da política pública de maior longevidade do país na área de segurança alimentar e nutricional, e considerado um dos mais abrangentes e duradouros programas na área de alimentação escolar do mundo. Entre 1995 e 2010, ampliou sua cobertura de 33,2 milhões para 45,6 milhões de escolares e os recursos financeiros passaram de 590,1 milhões para 3 bilhões de reais ${ }^{1}$.

Como uma Política Pública de enorme importância o PNAE vai avançando, adequando-se ao público atendido e à agricultura familiar. Os avanços têm possibilitado atender cada vez mais grupos de pessoas beneficiadas pelo programa e agregando valor aos produtos adquiridos da agricultura familiar. Mas, diante desse cenário de constantes avanços, o que se tem discutido e pesquisado no Brasil em termos de Políticas Públicas relacionadas ao Programa Nacional de Alimentação Escolar? Nesse prisma, formulou-se o seguinte problema de pesquisa: quais as tendências de pesquisa na área de Políticas Públicas que predominaram no Brasil no PNAE?

O objetivo do artigo é avaliar as tendências de pesquisa do Programa Nacional de Alimentação Escolar, analisando os periódicos disponibilizados pela Coordenação de Aperfeiçoamento de Pessoal de Nível Superior - CAPES, durante o período de 2008 a 2013.

$\mathrm{O}$ artigo está definido basicamente em cinco seções: esta introdução; o referencial teórico referente ao Programa Nacional de Alimentação Escolar; a metodologia de pesquisa; a apresentação e análise dos resultados; e a conclusão do artigo.

\section{Métodos}

A metodologia teve início na base teórica e foi até a coleta e análise dos dados. Para isso, a pesquisa selecionou, em junho de 2014, artigos em revistas disponibilizadas pelos Periódicos da CAPES. Sendo o fundamento básico de uma boa metodologia o vinculo com um plano de como alcançar os objetivos da questão pretendida. Considerando o objetivo pretendido, avaliar as tendências de pesquisa do Programa Nacional de Alimentação Escolar, analisando os periódicos disponibilizados pela Coordenação de Aperfeiçoamento de 
Pessoal de Nível Superior - CAPES, durante o período de 2008 a 2013, a metodologia adotada foi concebida como uma pesquisa bibliográfica e analises de dados qualitativa.

Para atingir o objetivo, os dados foram coletados e analisados a partir dos seguintes procedimentos:

a) Pesquisa no site dos periódicos da CAPES e separação dos artigos relacionados ao PNAE. Mas, inicialmente, sem delimitação de datas, a pesquisa observou os periódicos com publicação no tema de Alimentação Escolar (onde foram encontrados 633 artigos), Politicas Públicas (obteve-se 20.706 resultados de artigos) e Agricultura Familiar (com 4.377 artigos). Incluindo as três palavras-chave na busca, obteve-se 51 artigos que abordam os assuntos estudados. Delimitando o período da publicação, 2008 a 2013, foram definidos 41 artigos. Posteriormente, avaliaram-se os resumos e os problemas de pesquisa dos artigos, buscando assuntos relacionados com a área de alimentação escolar.

b) Leitura dos resumos e separação dos artigos de acordo com os enfoques: conceitual, aplicado e diagnóstico. Foram classificados como conceitual: os estudos que apresentaram objetivos de identificar, definir e explorar conceitos utilizados no PNAE; como aplicado: pesquisas que apresentaram alguma proposta; e como diagnóstico: estudos de análises e pesquisas de abordagens e tendências na área de estudo sobre o PNAE.

c) Classificação dos temas abordados, observando as convergências de assuntos. Após o ordenamento dos temas, foram selecionados 10 artigos, quando foi possível observar duas temáticas mais frequentes sobre o PNAE no período considerado.

\section{Resultados}

O foco central do artigo é avaliar as tendências de pesquisa do Programa Nacional de Alimentação Escolar, observando a limitação imposta pelo estudo com relação ao assunto abordado, bem como a restrição temporal.

Para a avaliação dos periódicos foi observado um conjunto de procedimentos. Após o enquadramento dos artigos nas condições previamente estabelecidas, foram selecionados 10 artigos dos seguintes periódicos: Revista Ciência \& Saúde Coletiva, Revista de Nutrição, Revista Saúde e Sociedade, Revista Agroalimentaria, Revista Brasileira de Epidemiologia.

\section{Pesquisa nos sites dos periódicos e} separação dos artigos relacionados ao PNAE

Conforme definido na metodologia, a seleção dos artigos ocorreu pela busca de palavras-chave, bem como pela leitura do resumo e das questões de pesquisa. A Tabela 1 apresenta a quantidade de artigos selecionados por periódico, considerando o período de 2008 a 2013.

Pela Tabela 1,60\% dos artigos selecionados foram publicados na Revista Ciência \& Saúde Coletiva, mostrando a relevância dos assuntos relacionados ao PNAE para esse periódico. Os demais periódicos, Revista de Nutrição, Revista Saúde e Sociedade, Revista Agroalimentaria e Revista Brasileira de Epidemiologia, contribuíram de forma equitativa para o estudo, totalizando $40 \%$ da amostra analisada.

\section{Análise metodológica \\ dos artigos relacionados ao PNAE}

O Quadro 1 apresenta a análise metodológica dos artigos selecionados, no qual foi contemplado o título, a natureza, o objetivo, a estratégia, a coleta de dados, a abrangência, a periodicidade e a análise de dados, dos periódicos e dos temas pesquisados.

Conforme o Quadro 1, dos artigos selecionados para este estudo, 6 apresentam fonte de coletas de dados primários e 4 secundários. Verificase uma predominância na abordagem qualitativa (8 artigos).

A abrangência dos estudos foi assim distribuída: 3 Nacionais, 6 regionais (dois no estado de São Paulo e um para os estados do Rio Grande do Sul, Minas Gerais, Goiás e Bahia, e 1 local no nordeste. No ano de 2010 foram realizados 5 artigos, os demais foram feitos em 2005, 2008, 2011 e 2012 .

Tabela 1. Quantidade de artigos selecionados por periódico.

\begin{tabular}{lcc}
\hline \multicolumn{1}{c}{ Periódico } & Quantidade & Percentual \\
\hline Revista Ciência \& Saúde & 6 & $60 \%$ \\
Coletiva & & \\
Revista de Nutrição & 1 & $10 \%$ \\
Revista Saúde e Sociedade & 1 & $10 \%$ \\
Revista Agroalimentaria & 1 & $10 \%$ \\
Revista Brasileira de & 1 & $10 \%$ \\
Epidemiologia & & $100 \%$ \\
Total & 10 & \\
\hline
\end{tabular}

Fonte: Pesquisa (2014). 


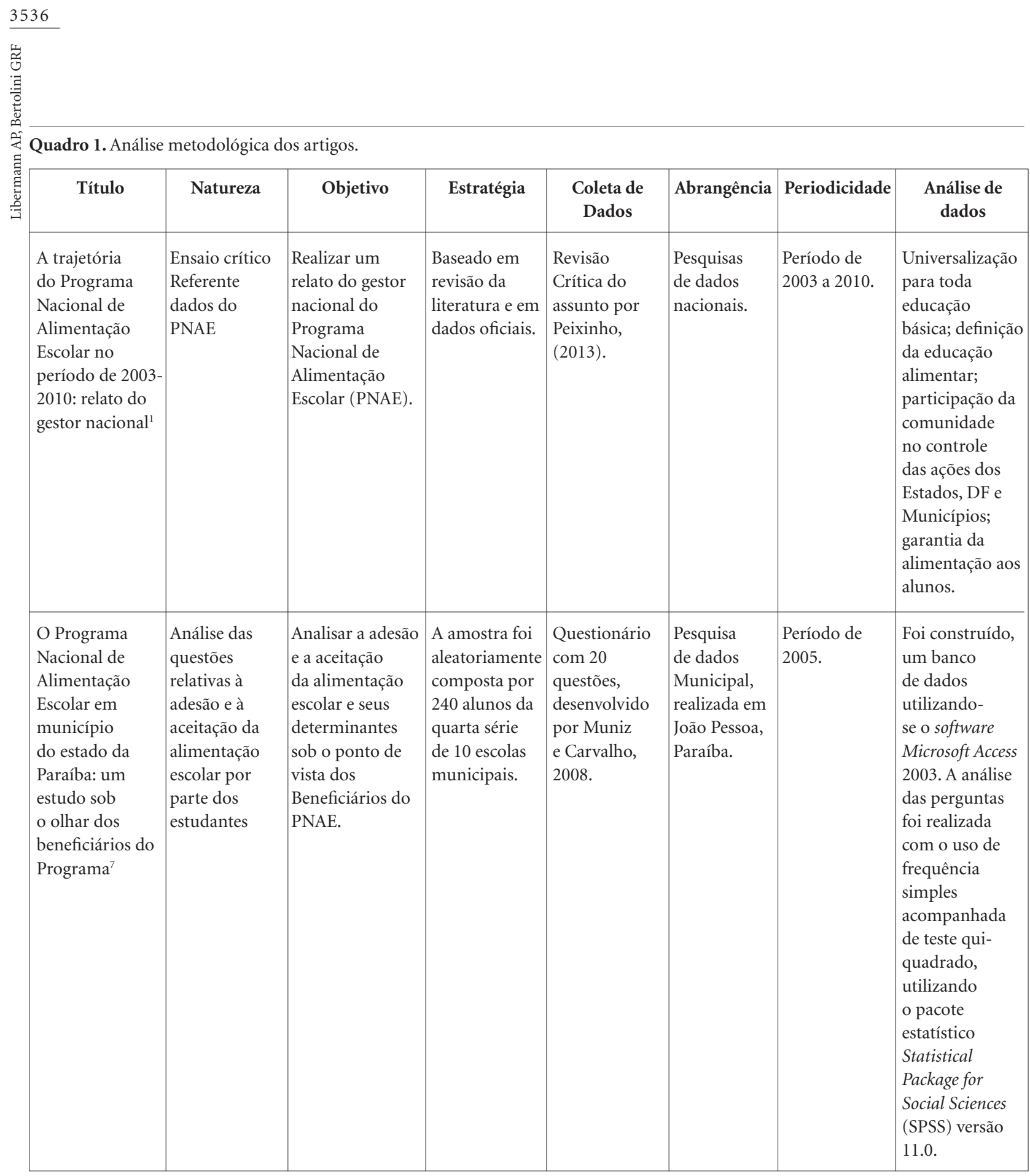

continua

\section{Temas abordados}

Dentro dos artigos científicos pesquisados que revelam as tendências da área de estudo sobre o PNAE, os temas mais abordados foram a alimentação escolar e a agricultura familiar pelo ponto de vista das regiões estudadas, de forma a atingir o objetivo da pesquisa. O Quadro 2 apresenta os artigos relacionados à alimentação escolar, abordada no âmbito interno das entidades escolares e desenvolvendo inúmeras áreas de discussão sobre o assunto.

Com relação a esse tema, há vários artigos publicados, enfatizando estudos na área de educação e segurança nutricionais que têm se mostrado importantes para a avaliação do PNAE no Brasil. 
Quadro 1. continuação

\begin{tabular}{|c|c|c|c|c|c|c|c|}
\hline Título & Natureza & Objetivo & Estratégia & $\begin{array}{c}\text { Coleta de } \\
\text { Dados }\end{array}$ & Abrangência & Periodicidade & $\begin{array}{l}\text { Análise } \\
\text { de dados }\end{array}$ \\
\hline $\begin{array}{l}\text { Alimentação } \\
\text { Escolar e } \\
\text { Agricultura } \\
\text { Familiar: } \\
\text { reconectando } \\
\text { o consumo à } \\
\text { produção }\end{array}$ & $\begin{array}{l}\text { Foi utilizado } \\
\text { estudo de caso } \\
\text { com técnicas } \\
\text { qualitativas } \\
\text { de } \\
\text { levantamento } \\
\text { e análise } \\
\text { de dados } \\
\text { bibliográficos } \\
\text { documentos } \\
\text { oficiais e } \\
\text { legislações. }\end{array}$ & $\begin{array}{l}\text { Abordar a } \\
\text { relação entre } \\
\text { consumo, } \\
\text { produção e } \\
\text { políticas públicas } \\
\text { alimentares } \\
\text { a partir do } \\
\text { Programa de } \\
\text { Alimentação } \\
\text { Escolar } \\
\text { (PAE) brasileiro. }\end{array}$ & $\begin{array}{l}\text { Foram } \\
\text { realizadas } 57 \\
\text { entrevistas, } \\
\text { divididos em } \\
\text { produtores } \\
\text { consumidores } \\
\text { e gestores. }\end{array}$ & $\begin{array}{l}\text { Critério de } \\
\text { amostra: } \\
\text { identificar } \\
\text { aquela que } \\
\text { fosse capaz } \\
\text { de refletir a } \\
\text { totalidade } \\
\text { nas suas } \\
\text { múltiplas } \\
\text { dimensões. } \\
\text { Critérios } \\
\text { referidos } \\
\text { por Minayo } \\
\text { (1996). }\end{array}$ & \begin{tabular}{|l|} 
Pesquisa \\
regional \\
de dois \\
municípios \\
situados no \\
Vale do Rio \\
dos Sinos e \\
Paranhana, \\
Rolante e \\
Dois Irmãos \\
- (RS)
\end{tabular} & $\begin{array}{l}\text { Período de } \\
2010 .\end{array}$ & $\begin{array}{l}\text { A análise dos } \\
\text { dados qualitativos } \\
\text { foi realizada pela } \\
\text { categorização } \\
\text { temática, } \\
\text { utilizando-se } \\
\text { o referencial } \\
\text { sobre análise de } \\
\text { conteúdo e o } \\
\text { software NVivo } 2 \\
\text { para auxiliar na } \\
\text { sistematização } \\
\text { das informações. } \\
\text { (Guizzo et al., } \\
\text { 2003). }\end{array}$ \\
\hline $\begin{array}{l}\text { Experiências de } \\
\text { programas } \\
\text { combinados } \\
\text { de alimentação } \\
\text { escolar e } \\
\text { desenvolvimento } \\
\text { local em São } \\
\text { Paulo-Brasil }\end{array}$ & $\begin{array}{l}\text { Estudo } \\
\text { de caráter } \\
\text { transversal e } \\
\text { descritivo }\end{array}$ & $\begin{array}{l}\text { Estimar o efeito } \\
\text { dos programas } \\
\text { de alimentação } \\
\text { escolar e } \\
\text { desenvolvimento } \\
\text { rural nas } \\
\text { dimensões: } \\
\text { melhoria das } \\
\text { condições } \\
\text { de vida dos } \\
\text { agricultores, } \\
\text { desenvolvimento } \\
\text { local e a } \\
\text { qualidade da } \\
\text { alimentação } \\
\text { servida aos } \\
\text { escolares. }\end{array}$ & $\begin{array}{l}\text { Amostra } \\
\text { de estudantes, } \\
\text { de } 7 \text { a } 14 \\
\text { anos de escolas } \\
\text { públicas e } \\
\text { entrevista com } \\
\text { produtores. }\end{array}$ & \begin{tabular}{|l} 
Foi aplicado o \\
plano amostral \\
estratificado. \\
Considerando \\
$17 \%$ de \\
sobrepeso, \\
nível de \\
confiança \\
$95 \%$, erro \\
amostral \\
0,05 . Foram \\
sorteados 195 \\
escolares em \\
Tambaú e \\
200 em Casa \\
Branca, com \\
programa R \\
2.9.0.
\end{tabular} & \begin{tabular}{|l|} 
Pesquisa \\
regional \\
com dois \\
municípios \\
Tambaú e \\
Casa Branca \\
(SP).
\end{tabular} & $\begin{array}{l}\text { Período de } \\
2010 \text { a } 2011 .\end{array}$ & $\begin{array}{l}\text { A análise } \\
\text { qualitativa } \\
\text { considerou os seis } \\
\text { grupos } \\
\text { alimentares } \\
\text { componentes } \\
\text { do cardápio e } \\
\text { indicadores } \\
\text { complementares, } \\
\text { em um total de } \\
12 \text { componentes } \\
\text { de avaliação para } \\
\text { gerar o Indicador } \\
\text { de Qualidade } \\
\text { para Cardápios } \\
\text { da Alimentação } \\
\text { Escolar (Domene } \\
\text { et al., 2011). }\end{array}$ \\
\hline $\begin{array}{l}\text { Alimentação } \\
\text { na escola e } \\
\text { autonomia } \\
\text { - desafios e } \\
\text { possibilidades }^{6}\end{array}$ & $\begin{array}{l}\text { Ensaio crítico } \\
\text { através de } \\
\text { pressuposições } \\
\text { teóricas, } \\
\text { revisões } \\
\text { bibliográficas. }\end{array}$ & \begin{tabular}{|l} 
Evidenciar \\
a alimentação \\
na escola como \\
política \\
na promoção da \\
autonomia dos \\
estudantes por \\
meio de uma \\
educação \\
alimentar e \\
nutricional, \\
integrada pelos \\
diferentes atores \\
e sob a ótica da \\
cidadania.
\end{tabular} & $\begin{array}{l}\text { Baseado em } \\
\text { revisão da } \\
\text { literatura e } \\
\text { análises de } \\
\text { dados, debates, } \\
\text { projeto } \\
\text { pedagógico. }\end{array}$ & \begin{tabular}{|l} 
Revisão \\
Crítica do \\
assunto por \\
Barbosa et al. \\
$(2013)$.
\end{tabular} & $\begin{array}{l}\text { Pesquisas } \\
\text { de dados } \\
\text { nacionais. }\end{array}$ & $\begin{array}{l}\text { Período de } \\
2013 .\end{array}$ & $\begin{array}{l}\text { Conquistas } \\
\text { que na atualidade } \\
\text { tem se verificado } \\
\text { em relação à } \\
\text { constituição e à } \\
\text { implementação } \\
\text { de uma Política } \\
\text { Nacional de } \\
\text { Educação } \\
\text { Alimentar e } \\
\text { Nutricional, na } \\
\text { perspectiva da } \\
\text { realização do } \\
\text { Direito } \\
\text { Humano a } \\
\text { Alimentação } \\
\text { Adequada e } \\
\text { Saudável. }\end{array}$ \\
\hline
\end{tabular}




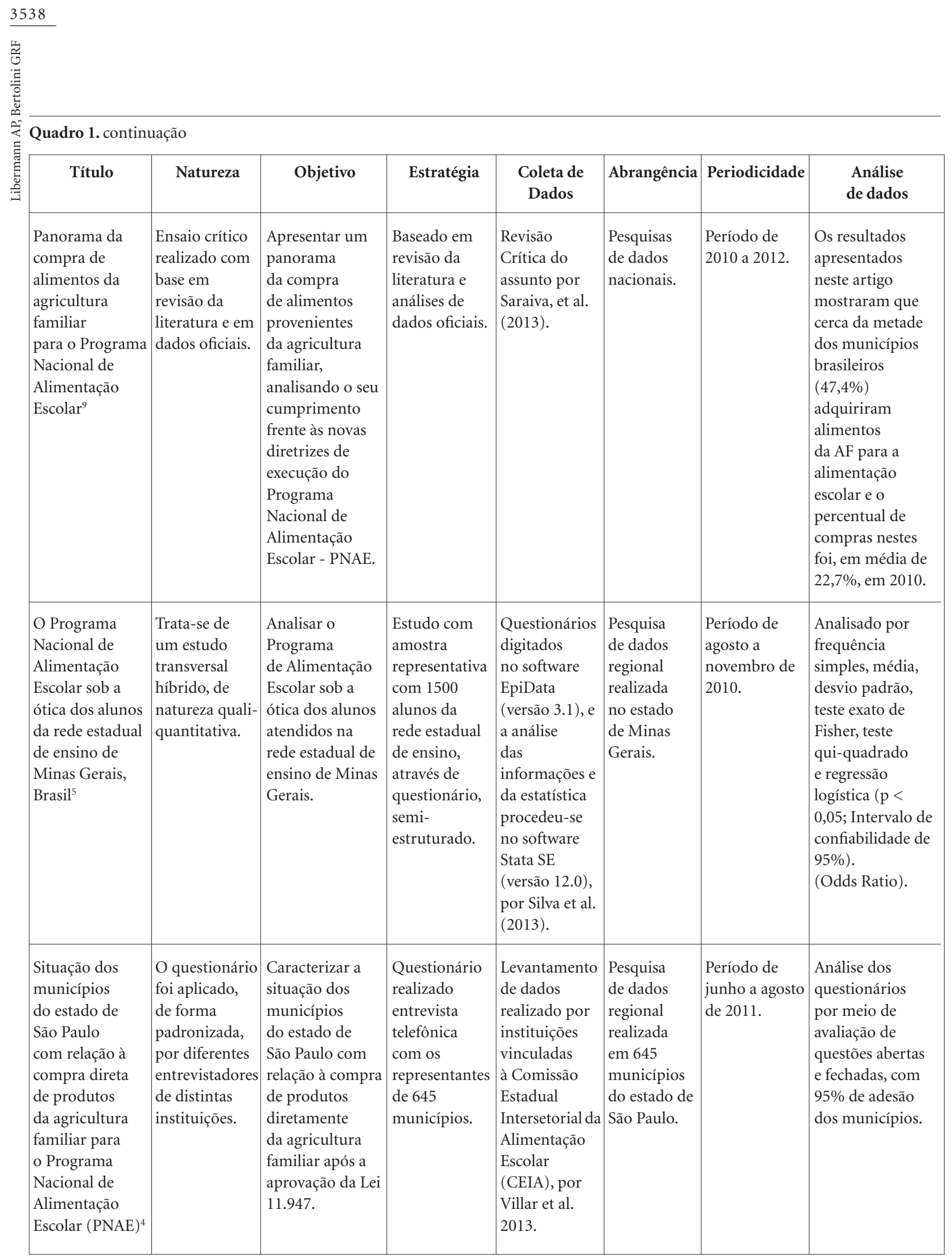

Conforme os estudos de Barbosa $^{6}$, o Programa Nacional de Alimentação Escolar constitui- se uma ação política que favorece pensar concepções e conceitos que engendram práticas em 


\begin{tabular}{|c|c|c|c|c|c|c|c|}
\hline \multicolumn{8}{|c|}{ Quadro 1. continuação } \\
\hline Título & Natureza & Objetivo & Estratégia & $\begin{array}{c}\text { Coleta de } \\
\text { Dados }\end{array}$ & Abrangência & Periodicidade & $\begin{array}{l}\text { Análise } \\
\text { de dados }\end{array}$ \\
\hline $\begin{array}{l}\text { Alimentação } \\
\text { escolar nas } \\
\text { comunidades } \\
\text { quilombolas: } \\
\text { desafios e } \\
\text { potencialidades }{ }^{10}\end{array}$ & $\begin{array}{l}\text { Relato de } \\
\text { experiência } \\
\text { associado à } \\
\text { sistematização } \\
\text { da literatura } \\
\text { sobre o PNAE, } \\
\text { SAN e outras } \\
\text { políticas. }\end{array}$ & $\begin{array}{l}\text { Discutir os } \\
\text { desafios e as } \\
\text { potencialidades } \\
\text { da alimentação } \\
\text { escolar nas } \\
\text { comunidades } \\
\text { quilombolas, } \\
\text { através do } \\
\text { Centro Col. em } \\
\text { Alimentação/ } \\
\text { Nutrição do } \\
\text { Escolar da Um. } \\
\text { Federal de Goiás } \\
\text { / Centro-Oeste). }\end{array}$ & $\begin{array}{l}\text { Baseado em } \\
\text { revisão da } \\
\text { literatura e } \\
\text { análises de } \\
\text { dados do } \\
\text { Centro de } \\
\text { Alimentação } \\
\text { e Nutrição } \\
\text { do Escolar da } \\
\text { Universidade } \\
\text { Federal de } \\
\text { Goiás e Região } \\
\text { Centro-Oeste. }\end{array}$ & $\begin{array}{l}\text { Revisão } \\
\text { Crítica do } \\
\text { assunto por } \\
\text { Sousa, et al. } \\
(2013) \text {. }\end{array}$ & $\begin{array}{l}\text { Pesquisa } \\
\text { de dados } \\
\text { regional no } \\
\text { estado de } \\
\text { Goiás. }\end{array}$ & $\begin{array}{l}\text { Período de } \\
2010 \text { a } 2013 .\end{array}$ & $\begin{array}{l}\text { Os resultados } \\
\text { apresentados } \\
\text { neste artigo } \\
\text { mostraram que } \\
\text { em } 2012 \text { ocorreu } \\
\text { uma oficina } \\
\text { para validação } \\
\text { do instrumento, } \\
\text { aplicado nas } 22 \\
\text { comunidades } \\
\text { quilombolas } \\
\text { goianas. Que } \\
\text { em } 2013 \text { estão } \\
\text { previstas } \\
\text { reuniões locais } \\
\text { para divulgação } \\
\text { dos resultados } \\
\text { e pactuação } \\
\text { de ações de } \\
\text { intervenção. }\end{array}$ \\
\hline $\begin{array}{l}\text { Escola: lugar } \\
\text { de estudar e de } \\
\text { comer }^{3}\end{array}$ & $\begin{array}{l}\text { Abordagem } \\
\text { qualitativa, a } \\
\text { partir } \\
\text { das narrativas } \\
\text { orais e escritas. }\end{array}$ & $\begin{array}{l}\text { Discutir } \\
\text { significados } \\
\text { sobre } \\
\text { alimentação } \\
\text { escolar } \\
\text { atribuídos por } \\
\text { estudantes em } \\
\text { escolas públicas } \\
\text { na Bahia. }\end{array}$ & $\begin{array}{l}\text { Participaram } \\
\text { do estudo } \\
160 \text { escolares } \\
\text { adolescentes } \\
\text { de } 12 \text { a } 18 \\
\text { anos, todos } \\
\text { das camadas } \\
\text { populares. }\end{array}$ & $\begin{array}{l}\text { Redações } \\
\text { sobre o tema } \\
\text { alimentação } \\
\text { na escola e } \\
\text { entrevistas } \\
\text { com } \\
\text { abordagem } \\
\text { qualitativa, } \\
\text { por Minayo e } \\
\text { Goldemberg, } \\
1994 .\end{array}$ & $\begin{array}{l}\text { Estudo } \\
\text { regional } \\
\text { realizado } \\
\text { em Salvador, } \\
\text { Bahia. }\end{array}$ & $\begin{array}{l}\text { Período letivo } \\
\text { de agosto de } \\
2007 \text { a junho } \\
\text { de } 2008 .\end{array}$ & $\begin{array}{l}\text { Elegeu-se dois } \\
\text { eixos } \\
\text { centrais } \\
\text { familiaridade e } \\
\text { estranhamento. } \\
\text { E divididos em } \\
\text { categorias:1) } \\
\text { "o lugar do } \\
\text { alimento"; 2) “o } \\
\text { não-lugar" ou } \\
\text { "fora-de-lugar" do } \\
\text { alimento; 3) a } \\
\text { noção de saudável } \\
\text { como bem. }\end{array}$ \\
\hline
\end{tabular}

Fonte: Pesquisa (2014).

torno da alimentação escolar tanto no que diz respeito às ações estratégicas para SAN quanto às políticas educacionais.

Verifica-se nas considerações de Peixinho ${ }^{1}$, que a grande conquista para o PNAE, veio com a publicação da Lei no 11.947 , que avança quando dispõe sobre alimentação escolar, universalizando o programa para toda educação básica, ou seja, da educação infantil ao ensino médio, além dos jovens e adultos. Barbosa et al. ${ }^{6}$ complementam que esta lei estabelece dois eixos de ação importantes: a oferta de alimentação escolar e as ações de educação alimentar e nutricional.
Por saudável, entende-se um tipo de alimentação que garante nutrientes necessários aos processos fisiológicos para o desenvolvimento físico e mental do indivíduo, em correspondência com os hábitos alimentares regionais, e mesmo reconhecendo essas noções, os escolares nem sempre fazem relação entre saúde e PNAE, consideram Freitas et al. ${ }^{3}$.

Muniz e Carvalho ${ }^{7}$ concluem que é importante referir o papel do programa como estratégia de educação nutricional para aquisição de bons hábitos alimentares, mais do que um Programa de suplementação alimentar, deve ser 


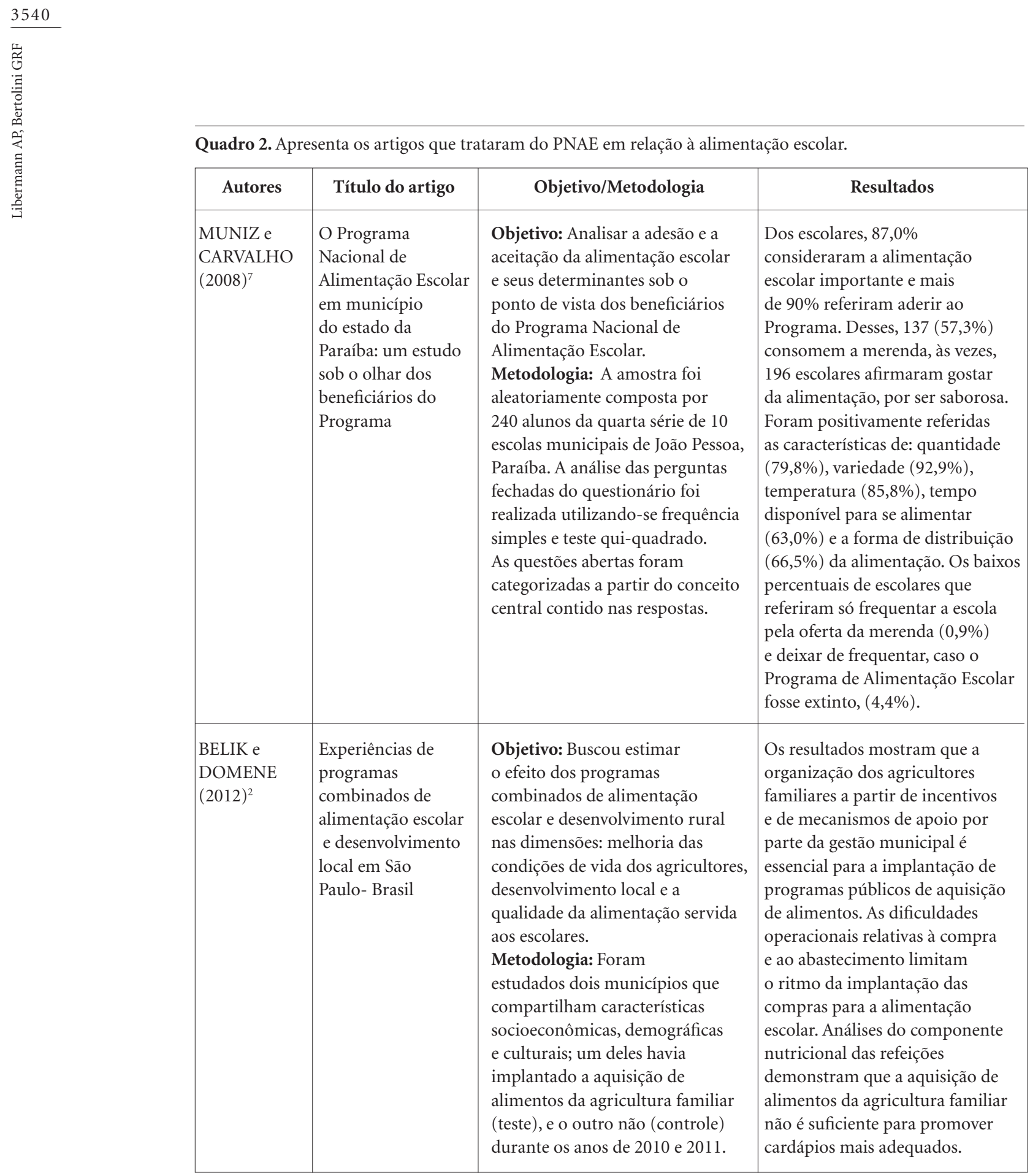

continua

visto como um importante instrumento de educação nutricional.

Os resultados dos estudos sobre alimentação escolar de Muniz e Carvalho ${ }^{7}$ mostraram que as crianças consideram a alimentação escolar importante, mas não uma condição para a sua permanência na escola, dados como estes tornam-se relevantes, considerando que o PNAE tem sido apontado como um Programa assistencialista para muitas crianças, que têm na alimentação escolar a sua principal refeição.

Nas considerações de Triches e Schneider ${ }^{8}$, um passo positivo foi dado a partir de $1994 \mathrm{com}$ a descentralização, pois a gestão da alimentação escolar pelos municípios possibilitou o planejamento dos cardápios segundo a cultura alimentar das comunidades e a maior participação da sociedade civil no gerenciamento do Programa. 


\begin{tabular}{|c|c|c|c|}
\hline \multicolumn{4}{|c|}{ Quadro 2. continuação } \\
\hline Autores & Título do artigo & Objetivo/Metodologia & Resultados \\
\hline $\begin{array}{l}\text { BARBOSA et } \\
\text { al. }(2013)^{6}\end{array}$ & $\begin{array}{l}\text { Alimentação na } \\
\text { escola e autonomia } \\
\text { - desafios e } \\
\text { possibilidades }\end{array}$ & $\begin{array}{l}\text { Objetivo: Evidenciar a } \\
\text { alimentação na escola como } \\
\text { importante política na promoção } \\
\text { da autonomia dos estudantes por } \\
\text { meio de uma educação alimentar } \\
\text { e nutricional desenvolvida de } \\
\text { modo curricular, integrado pelos } \\
\text { diferentes atores e sob a ótica da } \\
\text { cidadania. } \\
\text { Metodologia: As estratégias } \\
\text { envolveram educação alimentar } \\
\text { e nutricional com a presença } \\
\text { cotidiana de qualidade e } \\
\text { adequação na alimentação escolar, } \\
\text { de debates sobre as diversas } \\
\text { dimensões da alimentação no } \\
\text { currículo vivido e com integração } \\
\text { da alimentação no projeto } \\
\text { pedagógico estendido a vários } \\
\text { âmbitos do sistema de ensino. }\end{array}$ & $\begin{array}{l}\text { As conquistas que na atualidade } \\
\text { tem se verificado em relação à } \\
\text { constituição e à implementação } \\
\text { de uma Política Nacional de } \\
\text { Educação Alimentar e Nutricional, } \\
\text { na perspectiva da realização do } \\
\text { Direito Humano a Alimentação } \\
\text { Adequada e Saudável. }\end{array}$ \\
\hline $\begin{array}{l}\text { SILVA et al. } \\
(2013)^{5}\end{array}$ & $\begin{array}{l}\text { O Programa } \\
\text { Nacional de } \\
\text { Alimentação Escolar } \\
\text { sob a ótica } \\
\text { dos alunos da rede } \\
\text { estadual de ensino } \\
\text { de Minas Gerais, } \\
\text { Brasil }\end{array}$ & $\begin{array}{l}\text { Objetivo:Analisar o Programa } \\
\text { de Alimentação Escolar sob a } \\
\text { ótica dos alunos atendidos na } \\
\text { rede estadual de ensino de Minas } \\
\text { Gerais. } \\
\text { Metodologia: Trata-se de estudo } \\
\text { transversal, quali-quantitativo, } \\
\text { com amostra de } 1500 \text { alunos, } \\
\text { representativa do universo da } \\
\text { rede estadual de ensino de Minas } \\
\text { Gerais, utilizando questionário } \\
\text { semiestruturado analisado por } \\
\text { meio de frequência simples, } \\
\text { média, desvio padrão, teste exato } \\
\text { de Fisher, teste qui-quadrado e } \\
\text { regressão logística (p }<0,05 \text {; IC } \\
\text { 95\%). }\end{array}$ & $\begin{array}{l}\text { Houve efetiva aceitação de } 28,8 \% \\
\text { e efetiva adesão de } 45,1 \% \text { ao } \\
\text { Programa. No total, } 73,5 \% \text { dos } \\
\text { alunos sugeriram melhorias } \\
\text { para a Alimentação Escolar. } \\
\text { Muitos princípios e diretrizes } \\
\text { do programa não estão sendo } \\
\text { cumpridos. A aceitação } \\
\text { da Alimentação Escolar } \\
\text { mostrou-se negativamente } \\
\text { influenciada pelo consumo de } \\
\text { alimentos extrainstitucionais e } \\
\text { positivamente influenciada pelas } \\
\text { ações de Educação Alimentar e } \\
\text { Nutricional. }\end{array}$ \\
\hline
\end{tabular}

Belik e Domene ${ }^{2}$ avaliaram em seus estudos alguns problemas da alimentação: 1) Período de chegada dos alimentos às escolas; 2) a falta de funcionários prejudica o andamento da cozinha e o cardápio deveria ser mais diversificado; e, 3) algumas escolas não têm local específico para que os professores façam suas refeições.

Do ponto de vista pedagógico, Barbosa et al. ${ }^{6}$ consideram que para o processo de educação alimentar seja efetivo e alcance resultados, algumas ações parecem desejáveis: 1) A alimentação es- colar deve estar presente todos os dias letivos na escola com qualidade e adequação nutricional. 2) Os temas e os debates sobre alimentação devem garantir que todas as dimensões sejam abordadas: a dimensão econômica, social, cultural, etc. 3) É importante que o tema alimentação componha o projeto pedagógico, direcionando atividades transdisciplinares entre os docentes e demais profissionais. 4) As práticas de educação alimentar devem acontecer nos vários níveis da política e em vários âmbitos dos sistemas de ensino. 


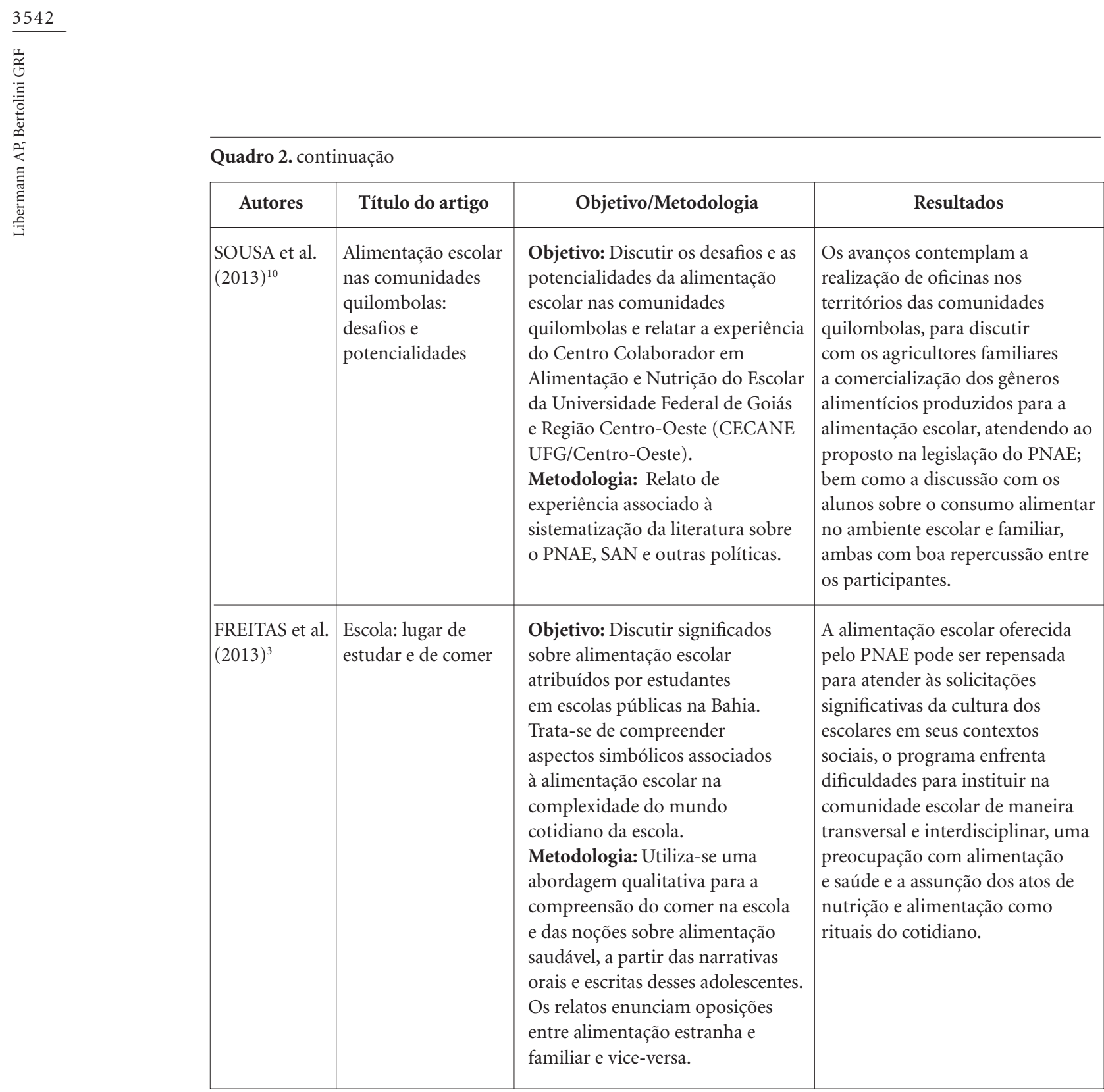

Fonte: Pesquisa (2014).

Barbosa et al. ${ }^{6}$ identificaram que a educação básica, com cerca de 42 milhões de estudantes, todos atendidos com uma ou mais refeições, de algum modo, mobiliza em torno do ato de alimentar-se na escola, quase um quarto da população brasileira.

Barbosa et al. ${ }^{6}$ também concluíram que por todos os temas discutidos, é possível perceber que o conceito de educação alimentar e nutricional nas escolas demanda um aporte conceitual e técnico pelos vários sujeitos envolvidos, constituindo um conjunto de ações pedagógicas, normativas e culturais, que se desenha nos vários espaços, como a universidade, a prefeitura, as secretarias de educação, de saúde e outros.

Em estudo realizado por Silva et al. ${ }^{5}$, a grande maioria $(70 \%)$ das sugestões de melhoria da alimentação escolar dizia respeito à variação e à inserção de mais frutas, verduras e legumes no cardápios, sendo que os principais desafios envolvidos na ampliação da adesão/aceitação das refeições perpassam pelo adequado planejamento do cardápio.

Vista dos vários ângulos, a educação alimentar e nutricional facilita ao estudante uma aproximação com várias informações e permitirá que 
este seja e sinta-se parte da política que normatiza e sustenta esse tema, considera em seus estudos Barbosa et al. ${ }^{\text {. }}$

O Quadro 3 apresenta os artigos relacionados à agricultura familiar, abordando inúmeras questões referentes ao apoio aos agricultores, produção de alimentos saudáveis etc.

Triches e Schneider ${ }^{8}$ concluíram que a Lei ${ }^{\circ}$ 11.947, tornou-se um marco nas políticas públicas, porque ampara explicitamente a agricultura familiar, tornando obrigatória a utilização de no mínimo 30\% do valor remetido às entidades executoras pelo FNDE na aquisição de gêneros alimentícios desses fornecedores.

Nas considerações de Saraiva et al. ${ }^{9}$, verifica-se que a compra da AF para o PNAE é uma regulamentação recente, a inviabilidade de fornecimento regular e constante como justificativa para o não atendimento dos 30\% exige articulação entre quem compra (demanda de alimentos

Quadro 3. Apresenta os artigos que trataram do PNAE em relação à agricultura familiar.

\begin{tabular}{|c|c|c|c|}
\hline Autores & Título do artigo & Objetivo/Metodologia & Resultados \\
\hline $\begin{array}{l}\text { PEIXINHO } \\
(2013)^{1}\end{array}$ & $\begin{array}{l}\text { A trajetória do } \\
\text { Programa Nacional } \\
\text { de Alimentação } \\
\text { Escolar } \\
\text { no período de 2003- } \\
\text { 2010: relato do } \\
\text { gestor nacional }\end{array}$ & $\begin{array}{l}\text { Objetivo: Realizar um relato do } \\
\text { gestor nacional do Programa } \\
\text { Nacional de Alimentação Escolar } \\
\text { (PNAE), com ênfase no período de } \\
2003 \text { a 2010. } \\
\text { Metodologia: Trata-se de um } \\
\text { ensaio crítico realizado com } \\
\text { base em revisão da literatura } \\
\text { e em dados oficiais fornecidos } \\
\text { pelo Fundo Nacional de } \\
\text { Desenvolvimento da Educação/ } \\
\text { Ministério da Educação (FNDE/ } \\
\text { MEC), instituição responsável pela } \\
\text { gestão do Programa no contexto } \\
\text { nacional. }\end{array}$ & $\begin{array}{l}\text { No período de } 1995 \text { a } 2010, \\
\text { observa-se uma importante } \\
\text { ampliação do PNAE, tanto } \\
\text { em termos de alocação de } \\
\text { recursos financeiros, cobertura } \\
\text { populacional e estratégias } \\
\text { operacionais, bem como em sua } \\
\text { concepção ou ressignificação } \\
\text { como política pública ou } \\
\text { programa social em alimentação } \\
\text { e nutrição do escolar no contexto } \\
\text { da sociedade brasileira. }\end{array}$ \\
\hline $\begin{array}{l}\text { TRICHES e } \\
\text { SCHNEIDER } \\
(2010)^{8}\end{array}$ & $\begin{array}{l}\text { Alimentação Escolar } \\
\text { e Agricultura } \\
\text { Familiar: } \\
\text { reconectando } \\
\text { o consumo à } \\
\text { produção }\end{array}$ & $\begin{array}{l}\text { Objetivo: Abordar a relação entre } \\
\text { consumo, produção e políticas } \\
\text { públicas alimentares a partir } \\
\text { do Programa de Alimentação } \\
\text { Escolar (PAE) brasileiro, } \\
\text { buscando entender como ocorre a } \\
\text { construção de cadeias alimentares } \\
\text { particulares que aproximam a } \\
\text { produção e o consumo e os efeitos } \\
\text { decorrentes. } \\
\text { Metodologia: Para a investigação } \\
\text { dessa temática, empregou-se o } \\
\text { estudo de caso e documental com } \\
\text { abordagem qualitativa. Foram } \\
\text { utilizados dados bibliográficos, } \\
\text { documentos oficiais e legislações } \\
\text { para contextualizar o panorama } \\
\text { alimentar e as políticas públicas } \\
\text { relativas à Segurança Alimentar } \\
\text { e Nutricional e ao Programa } \\
\text { Nacional de Alimentação Escolar. }\end{array}$ & $\begin{array}{l}\text { Observa-se como resultados } \\
\text { aparentes dessas novas relações } \\
\text { uma modificação no nível } \\
\text { do consumo alimentos mais } \\
\text { saudáveis e adequados no que } \\
\text { diz respeito à aceitação dos } \\
\text { alunos, uma revitalização com } \\
\text { novas perspectivas de mercado } \\
\text { para a agricultura familiar, e um } \\
\text { fomento às práticas de produção } \\
\text { consideradas menos nocivas ao } \\
\text { ambiente. Vislumbram-se, com } \\
\text { isto, sementes de um modelo de } \\
\text { desenvolvimento que promove } \\
\text { não só crescimento econômico } \\
\text { como também justiça social, } \\
\text { conservação ambiental e saúde } \\
\text { pública. }\end{array}$ \\
\hline
\end{tabular}




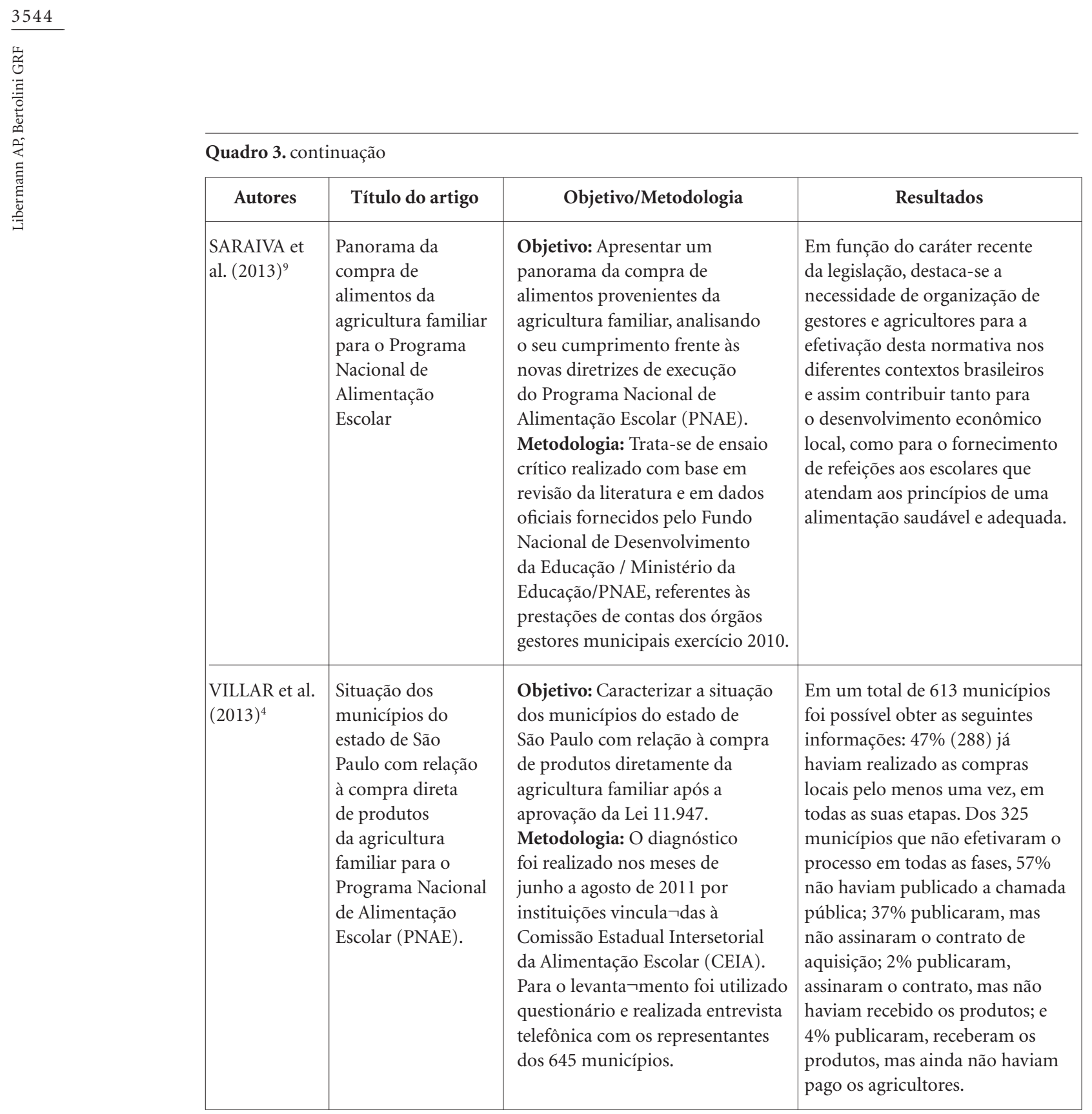

Fonte: Pesquisa (2014).

para as escolas dos municípios) e quem vende (oferta de alimentos produzidos pelos agricultores familiares).

Destaca-se que o planejamento dos cardápios escolares e a verificação das características dos diferentes produtos (sazonalidade) interferem no abastecimento 9 .

Em estudo realizado por Belik e Domene ${ }^{2}$, verificou-se que os produtores com terras menores (em torno de 30 hectares) e aqueles possuidores de estufas aumentaram sua produção e/ou passaram a realizar investimentos em suas propriedades a partir da demanda institucional, o que lhes dá condições de alcançar outros mercados com produtos de qualidade superior.

Mas, ainda segundo Belik e Domene ${ }^{2}$, a execução do PNAE leva a um permanente fonte de conflito entre os fornecedores de alimentos e serviços de alimentação para as prefeituras e os produtores e comércio local. Atualmente o PNAE conta com mais de US\$ 1,9 bilhão que são repassados aos municípios contra menos de US\$ 630 milhões no início da década passada.

Outra inovação qualificou a inspeção sanitária, realizada tanto na propriedade quanto na Central, com a criação do SIM (Serviço de Inspe- 
ção Municipal); o controle de qualidade dos produtos é complementado pela vistoria do pessoal da Alimentação Escolar no momento da entrega ${ }^{2}$.

Saraiva et al. ${ }^{9}$ destacam que apesar da obrigatoriedade da compra da agricultura familiar, alguns municípios ainda encontram dificuldades na aquisição destes alimentos devido à presença de grandes empresas do setor envolvidas na compra pública de alimentos.

Segundo Saraiva et al. ${ }^{9}$, a alimentação escolar é fator de desenvolvimento local, pois ganha reforços que estimulam os agricultores familiares e permitem que sejam alcançados os seus objetivos, trazendo ganhos para escolares, agricultores e comunidade local.

O desenvolvimento local será potencializado na medida em que o gestor público implemente a compra da agricultura familiar como uma ação transversal, prevendo desafios como assessoria técnica para agricultores, logística e armazenagem, diagnóstico e interação agrícola local/ regional e a criação de fóruns participativos de planejamento'.

O principal entrave para a compra de AF é a falta de planejamento, ou planejamento inadequado, do gestor para a execução da compra. Deve-se conhecer a realidade local dos agricultores para que o gestor possa planejar sua compra respeitando sazonalidades, vocação produtiva, etc. ${ }^{9}$.

Destacam, conforme os estudos de Sousa et al. ${ }^{10}$, que os avanços no PNAE contemplam a realização de oficinas nos territórios das comunidades quilombolas, para discutir com os agricultores familiares a comercialização dos gêneros alimentícios produzidos para a alimentação escolar.

Em relação à inserção de produtos da agricultura familiar na merenda escolar, o departamento de compras do município e a nutricionista acreditam que principal dificuldade seria adaptá-los à qualidade e especificações exigidas por eles, além do desperdício de verduras e legumes, alimentos de baixa aceitação entre os escolares².

\section{Conclusão}

O presente artigo teve como objetivo avaliar as tendências de pesquisa do Programa Nacional de Alimentação Escolar, durante o período de 2008 a 2013, limitando-se aos artigos publicados nos periódicos disponibilizados pela Coordenação de
Aperfeiçoamento de Pessoal de Nível Superior CAPES.

Foram analisados 10 artigos de cinco periódicos diferentes, selecionados pelas palavras-chave relacionadas ao assunto, bem como pelos resumos e problemas de pesquisa.

No desenvolvimento do trabalho, os artigos foram separados por dois enfoques: alimentação escolar e agricultura familiar. Por fim, verificouse que as temáticas mais abordadas na área de estudo do PNAE foram: 6 artigos de alimentação escolar e 4 de agricultura familiar.

Apesar de a alimentação escolar ter sido considerada importante frente às dificuldades financeiras das famílias, o sabor das preparações, bem como a adequação dos cardápios aos hábitos alimentares dos escolares, parece exercer forte influência na assiduidade destes ao PNAE.

Quanto aos agricultores, a estabilidade de renda decorrente da parceria viabilizou melhorias técnicas e de organização das suas atividades, pelo aumento da sua capacidade de investimento, além de diversificação da produção que oferece mais alternativas de comercialização dos seus produtos.

O escopo deste estudo foi limitado a 10 artigos científicos, tendo em vista as restrições previamente estabelecidas pelo problema de pesquisa apresentado, porém serve como ponto de partida para futuros estudos de enfoque das políticas públicas relacionadas ao PNAE. Dessa forma, o desenvolvimento do artigo de revisão contribuiu para a identificação dos principais temas e das tendências de estudo no PNAE dentro do contexto nacional.

Com isso, conclui-se que as principais tendências de pesquisa na área de políticas públicas que predominam no Brasil através do Programa de Alimentação Escolar, se caracterizam pelo estudo de estratégias de Segurança Alimentar e Nutricional, analisando a composição e a aceitação dos alimentos oferecidos aos estudantes pela analise da produção, melhores condições de vida e desenvolvimento local dos produtores rurais. Além disso, através do programa pode-se analisar e discutir os desafios e as potencialidades da alimentação escolar, em reuniões e debates sobre os problemas associados à produção e ao desenvolvimento rural e aqueles relacionados ao consumo e à saúde pública, abrindo um amplo campo de estudos. 


\section{Colaboradores}

AP Libermann realizou coleta e a analise dos dados, elaborou a versão inicial e aprovou a versão final; GRF Bertolini delineou o estudo, deu contribuições substanciais ao manuscrito e aprovou a versão final.

\section{Referências}

1. Peixinho AML. A trajetória do Programa Nacional de Alimentação Escolar no período de 2003-2010: relato do gestor nacional. Cien Saude Colet 2013; 18(4):909916.

2. Belik W, Domene SMA. Experiências de programas combinados de alimentação escolar e desenvolvimento local em São Paulo - Brasil. Agroalimentaria 2012; 18(34):57-72.

3. Freitas MCS, Minayo MCS, Ramos LB, Fontes GV, Santos LA, Souza EC, Santos AC, Mota SE, Paiva JB, Bernardelli TM, Demétrio F, Menezes I. Escola: lugar de estudar e de comer. Cien Saude Colet 2013; 18(4):979985.

4. Villar BS, Schwartzman F, Januario BL, Ramos JF. Situação dos municípios do estado de São Paulo com relação à compra direta de produtos da agricultura familiar para o Programa Nacional de Alimentação Escolar (PNAE). Rev Brasileira Epidemiologia 2013; 16(1):223-226.

5. Silva CAM, Marques LA, Bonomo E, Bezerra OMPA, Corrêa MS, Passos LSF, Souza A A, Barros BF, Souza DMS, Reis JÁ, Andrade NG. O Programa Nacional de Alimentação Escolar sob a ótica dos alunos da rede estadual de ensino de Minas Gerais, Brasil. Cien Saude Colet 2013; 18(4):963-969.

6. Barbosa NVS, Machado NMV, Soares MCV, Pinto ARR. Alimentação na escola e autonomia - desafios e possibilidades. Cien Saude Colet 2013; 18(4):937-945.

7. Muniz VM, Carvalho AT. O Programa Nacional de Alimentação Escolar em município do estado da Paraíba: um estudo sob o olhar dos beneficiários do Programa. Nutrição 2008; 20(3):285-296.

8. Triches RM, Schneider S. Alimentação Escolar e Agricultura Familiar: reconectando o consumo à produção. Saude Soc. 2010; 19(4):933-945.

9. Saraiva EB, Silva APF, Sousa AA, Cerqueira GF, Chagas CMS, Toral N. Panorama da compra de alimentos da agricultura familiar para o Programa Nacional de Alimentação Escolar. Cien Saude Colet 2013; 18(4):927936.

10. Sousa LM, Martins KA, Cordeiro MM, Monego ET, Silva SU, Alexandre VP. Alimentação escolar nas comunidades quilombolas: desafios e potencialidades. Cien Saude Colet 2013; 18(4):987-992.

Artigo apresentado em 23/10/2014

Aprovado em 01/12/2014

Versão final apresentada em 03/12/2014 